Correction

\title{
Correction: Nguyen, K.A.; Chen, W. DEM- and GIS-Based Analysis of Soil Erosion Depth Using Machine Learning. ISPRS Int. J. Geo-Inf. 2021, 10, 452
}

\author{
Kieu Anh Nguyen (1) and Walter Chen *(1)
}

check for

updates

Citation: Nguyen, K.A.; Chen, W. Correction: Nguyen, K.A.; Chen, W. DEM- and GIS-Based Analysis of Soil Erosion Depth Using Machine Learning. ISPRS Int. J. Geo-Inf. 2021, 10, 452. ISPRS Int. J. Geo-Inf. 2021, 10, 724. https://doi.org/10.3390/ ijgi10110724

Received: 27 August 2021

Accepted: 1 October 2021

Published: 27 October 2021

Publisher's Note: MDPI stays neutral with regard to jurisdictional claims in published maps and institutional affiliations.

Copyright: (c) 2021 by the authors. Licensee MDPI, Basel, Switzerland. This article is an open access article distributed under the terms and conditions of the Creative Commons Attribution (CC BY) license (https:// creativecommons.org/licenses/by/ $4.0 /)$.
Department of Civil Engineering, National Taipei University of Technology, Taipei 10608, Taiwan; t106429401@ntut.edu.tw

* Correspondence: waltchen@ntut.edu.tw; Tel.: +886-2-27712171 (ext. 2628)

(1) The last four numbers in the second column (No. of Factors) of Table 3 should read $15,15,16$, and 16 (instead of 16, 16, 19, and 19)

Original:

Table 3. Performance comparison of machine learning models using threefold cross-validation.

\begin{tabular}{cccccc}
\hline Model and Factors & No. of Factors & Average RMSE $(\mathbf{m m} / \mathbf{y r})$ & \multicolumn{2}{c}{ Average NSE } \\
\hline & & Training & Test & Training & Test \\
\hline RF (all) & 36 & 0.96 & 2.01 & 0.83 & 0.25 \\
\hline GBM (all) & 36 & 0.88 & 1.84 & 0.84 & 0.39 \\
\hline RF (confirmed) & 16 & 1.08 & 1.91 & 0.79 & 0.31 \\
\hline GBM (confirmed) & 16 & 0.79 & 1.50 & 0.88 & 0.59 \\
\hline RF (nonrejected) & 19 & 1.09 & 1.96 & 0.79 & 0.27 \\
\hline GBM (nonrejected) & 19 & 0.82 & 1.52 & 0.87 & 0.57
\end{tabular}

Corrected:

Table 3. Performance comparison of machine learning models using threefold cross-validation.

\begin{tabular}{cccccc}
\hline Model and Factors & No. of Factors & Average RMSE (mm/yr) & \multicolumn{2}{c}{ Average NSE } \\
\hline & & Training & Test & Training & Test \\
\hline RF (all) & 36 & 0.96 & 2.01 & 0.83 & 0.25 \\
\hline GBM (all) & 36 & 0.88 & 1.84 & 0.84 & 0.39 \\
\hline RF (confirmed) & 15 & 1.08 & 1.91 & 0.79 & 0.31 \\
\hline GBM (confirmed) & 15 & 0.79 & 1.50 & 0.88 & 0.59 \\
\hline RF (nonrejected) & 16 & 1.09 & 1.96 & 0.79 & 0.27 \\
\hline GBM (nonrejected) & 16 & 0.82 & 1.52 & 0.87 & 0.57 \\
\hline
\end{tabular}

(2) The last parentheses on page 13 (4.3 Model Prediction) should contain the numbers 15 and 16 (instead of 16 and 19)

Original:

They both have a similar appearance because they used a similar number of variables (16 and 19). 


\section{Corrected:}

They both have a similar appearance because they used a similar number of variables (15 and 16).

The authors apologize for any inconvenience caused and state that the scientific conclusions are unaffected. The original article has been updated.

\section{Reference}

1. Nguyen, K.A.; Chen, W. DEM- and GIS-Based Analysis of Soil Erosion Depth Using Machine Learning. ISPRS Int. J. Geo-Inf. 2021, 10, 452. [CrossRef] 